\title{
Implementasi Secure Socket Layer pada Aplikasi Computer Assisted Test Komisi Pemilihan Umum Bengkalis
}

\author{
Agus Tedyyana ${ }^{1}$ \\ ${ }^{1}$ Politeknik Negeri Bengkalis \\ (Program Studi Rekayasa Perangkat Lunak Jurusan Teknik Informatika) \\ Jl. Bathin Alam, Sungai Alam Bengkalis Riau, telp +62 (766) 24566 \\ e-mail: agustedyyana@polbeng.ac.id
}

\begin{abstract}
Abstrak
Sistem ujian menggunakan kertas yang selama ini biasa digunakan sering mengalami banyak masalah dalam pelaksanaanya, misalnya dalam pembulatan lingkaran, peserta terkadang sulit untuk melingkari dengan baik, kertas yang sensitif juga bisa rusak atau kotor karena harus mengganti jawaban lingkaran apabila salah saat melingkarinya. Faktor kecurangan merupakan kendala yang paling besar, seiring dengan perkembangan teknologi, untuk mengatasi kendala semua itu penulis merancang suatu sistem yang jauh lebih mudah dalam pelaksanan proses ujian yaitu dengan membuat sistem secara komputerisasi. Metode Computer Assisted Test didefinisikan sebagai tes atau penilaian yang diberikan oleh komputer baik yang bersifat stand-alone maupun yang bersifat dedicated network. Penggunaan Secure Socket Layer (SSL) bertujuan untuk menjaga informasi atau data selama dalam proses pengiriman melalui Internet dengan cara mengenkripsi sehingga hanya penerima informasi yang dapat memahami dari hasil enkripsi tersebut, ini sangat penting karena informasi yang dikirimkan diilnternet membutuhkan proses perjalanan dari komputer ke komputer sampai mencapai server tujuan.Tujuan dari penelitian ini adalah membuat sambuangan secara aman Aplikasi Computer Assisted Test Komisi Pemilihan Umum Bengkalis menggunakan SSL
\end{abstract}

Kata kunci: Computer Assisted Test, Secure Socket Layer

\begin{abstract}
The examination system uses paper which has been commonly used often to experience many problems in its implementation, for example in rounding circles, participants sometimes find it difficult to circle well, sensitive paper can also be damaged or dirty because they have to replace the circle's answers if it is wrong when circling them. The cheating factor is the biggest obstacle, along with the development of technology, to overcome these obstacles, the authors design a system that is much easier in carrying out the examination process, namely by making a computerized system. The Computer Assisted Test method is defined as a test or assessment given by a computer that is both stand-alone and dedicated network. The use of Secure Socket Layer (SSL) aims to safeguard information or data during the process of sending over the Internet by encrypting it so that only the recipient of the information can understand the encryption results, this is very important because the information sent on the Internet requires a process of traveling from computer to computer until reach the destination server. The purpose of this research is to make a safe discharge of Computer Assisted Test Application Bengkalis General Election Commission using SSL
\end{abstract}

Keywords: Computer Assisted Test, Secure Socket Layer 


\section{Pendahuluan}

Di era kehidupan bernegara pada saat ini, peran Komisi Pemilihan Umum di Indonesia sangat berpengaruh dalam tatanan sistem pemerintahan Indonesia guna mewujudkan keberhasilan pemilihan kepala pemerintahan yang baik. Oleh karena itu, perlu adanya perubahan pada sistem rekrutmen anggota panitia pemilihan kecamatan (PPK) untuk Ppemilihan bupati dan wakil bupati tahun 2020 terutama di kabupaten Bengkalis, dalam penyerapan sumber daya manusia (SDM) guna meningkatkan kompetensi dan integritas. Peningkatan kualitas SDM ini dirasa perlu dilakukan, karena sumber daya yang paling berperan penting dalam keberhasilan tata kelola pemerintahan suatu negara adalah manusia. Salah satu tahapan yang penting dilakukan dalam peningkatan kualitas SDM terletak ditahapan rekrutmen dan seleksi calon panitia pemilihan kecamatan.

Perkembangan teknologi saat ini yang sedemikian pesat, menyebabkan ujian tes dalam berbagai bidang juga turut mengalami peningkatan dalam kualitas, kecepatan, kepraktisan, serta kemudahan, Ujian konvensional yang biasanya menggunakan kertaspun bergeser kearah komputerisasi, salah satunya dengan adanya ujian online dan Computer Assisted Test (CAT).[1] tujuan dengan ujian Computer Assisted Test terwujud transparansi dalam seleksi administrasi anggota Panitia Pemilihan Kecamatan (PPK) untuk pemilihan bupati dan wakil bupati Tahun 2020 di kabupaten Bengkalis, juga untuk mendapatkan hasil ujian yang benar- benar real yang didapatkan oleh setiap peserta tanpa ada kecurangan dari pihak manapun.

Ujian menggunakan komputer atau Computer Assisted Test merupakan salah satu cara atau metode ujian dengan menggunakan alat bantu komputer yang bertujuan untuk mendapatkan suatu standar minimal kompetensi dasar bagi pelamar [2], Salah satu manfaat utama yang disediakan oleh aplikasi Computer Assisted Test ini adalah untuk menghasilkan efektivitas dan efisiensi dalam pelaksanaan tes, terlihat dari pengumuman hasil tes tanpa harus menunggu lama bisa langsung dapat dilihat. [3] Tes ini juga dapat meminimalisir kecurangan antara sesama peserta tes.

Pada penelitian sebelumnya oleh Khusnul Khatimah dengan judul "Pengembangan Prototipe Computer Assisted Test Menggunakan Arsitektur Model View Controller Pada Badan Kepegawaian Negara" [2] Berikutnya penelitian oleh Utami Mizani Putri dan Sri Rahayu dengan judul "Aplikasi Computer Based Test Sebagai Alternatif Evaluasi Hasil Pembelajaran Siswa" menyebutkan Persentase kelayakan pengguna aplikasi yang dibuat berdasarkan faktor usability testing secara umum dapat disimpulkan bahwa sistem aplikasi ujian berbasis computer memiliki kualitas baik dan sangat layak untuk proses pengolahan data akademik siswa, [4] Selanjutnya penelitian yang dilakukan oleh Ferry Putrawansyah degan judul "Aplikasi Computer Assisted Test Pada Penerimaan Mahasiswa Baru Sekolah Tinggi Teknologi Pagar Alam ", hasil dari penelitian ini menerapkan Aplikasi Computer Assisted Test pada test penerimaan mahasiswa baru di sekolah tinggi teknologi pagar alam, [3] ketiga penelitian sebelumnya belum diterapkan teknik pengamanan system terhadap aplikasi CAT yang dibuat sehingga memungkinkan terjadinya perpindahan data yang tidak aman padahal Faktor terpenting yang harus diperhatikan saat sebuah website diakses adalah keamanan, sejak dulu hingga saat ini internet diasumsikan sebagai dunia digital yang sangat luas, dimana setiap pengguna harus berhati-hati karena sangat sedikitnya pilihan serta perangkat untuk menjamin keamanan akses di internet, hal ini diperkuat sesuai dengan laporan pusat operasi keamanan cyber nasional, Sepanjang tahun 2019, sistem monitoring mata garuda Indonesia melalui laporan tahunan mendeteksi adanya sekitar 290,3 juta serangan siber ke jaringan internet Indonesia. Terbesar adalah serangan percobaan pembocoran data, diikuti dengan serangan menggunakan metoda malware. 
Secure Socket Layer merupakan sebuah cara agar situs web membuat sambungan aman dengan browser web pengguna, validasi sertifikat dalam Secure Socket Layer atau Transport Layer Security protokol (SSL / TLS) sangat penting untuk keamanan Internet. [5] Secured Socket Layer telah banyak digunakan untuk otentikasi karena dapat mengamankan komunikasi antara pihak-pihak dalam mentransmisikan data terenkripsi antara browser web dan server. [6] Penggunanan Secure Socket Layer lebih direkomendasikan untuk digunakan sebagai mekanisme keamanan pada komunikasi end-to- end IoT middleware dengan subscriber berbasis protokol HTTP, dibandingkan dengan AES-256.[7]

Hypertext Transfer Protocol Secure (HTTPS) adalah Hypertext Transfer Protocol (HTTP) yang menggunakan secure socket layer yang dienkripsi yang dipanggil melalui web server yang menggunakan HTTPS. secure socket layer adalah jenis sockets communications yang berada diantara transmision control protocol/internet protocol dan application layer. secure socket layer biasanya berada antara server dan client untuk mengamankan sambungan. [8]

Penelitian ini bertujuan membuat sebuah aplikasi Computer Assisted Test yang didalamnya diterapkan teknik pengamanan system terhadap aplikasi menggunakan Secure Socket Layer sebagai pengaman antara client dan server sehingga komunukasi antara server dan client akan terenkrifsi dan menjadi lebih aman, ini di anggap sangat penting demi menjaga keamanan data saat perpindahan data dari server ke client ataupun sebaliknya.

\section{Metode Penelitian}

Dalam melakukan pengembangan aplikasi computer assisted test komisi pemilihan umum Bengkalis maka metode pengembangan yang digunakan adalah menggunakan metode waterfall. Metode ini merupakan metode klasik yang bekerja secara sistematis dan berurutan saat proses pegnembagan sistem informasi. Pada Gambar 1 dapat dilihat bagaimana proses pengembanga dengan waterfall. [9]

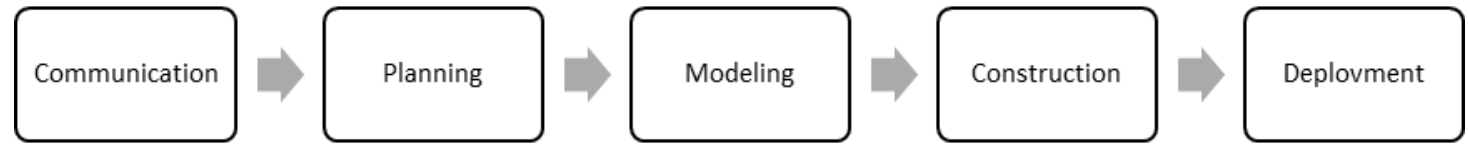

Gambar 1. proses pengembangan sistem dengan waterfall

- Communication, dalam tahap ini yang dilakukan adalah analisis untuk medapatkan kebutuhan system, selain itu juga dilakukan pengumpulan data yang dianggap perlu dalam proses pengembangan.

- Planning, dalam tahap ini proses yang dilakukan adalah perencanaan dalam pengerjaan aplikasi computer assisted test komisi pemilihan umum Bengkalis Perencanaan yang dibuat berupa timeline kegiatan yang harus diselesaikan dalam proses pengembangan.

- Modeling, dalam tahap ini yang dilakukan yaitu melakukan pembuatan model atau alur dari sistem aplikasi computer assisted test komisi pemilihan umum Bengkalis

- Construction, dalam tahap ini dilakukan pengkodean. Pengkodean yang dibuat mengikuti hasil modeling. Setelah selesai pengkodean dilakukan pengujian sistem baik secara local maupun secara online, dalam tahap pengkodean Web Development aplikasi yang digunakan adalah Laravel

- Deplovment, ini adalah tahapan akhir yaitu melakukan persiapan penggunaan product, juga dilakukan pemeliharaan terhadap product. Selain itu dilakukan uji coba terhadap produk menggunakan GtMetrix 


\section{Hasil dan Pembahasan}

\subsection{Sistem CAT}

Sistem CAT KPU dibangun berbasis web dengan beberapa lapisan (layer) keamanan terutama terkait naskah soal

- Layer I : Akses masuk ke sistem

Semua level pengguna yang terlibat untuk masuk ke sistem harus memiliki username dan password yang benar.

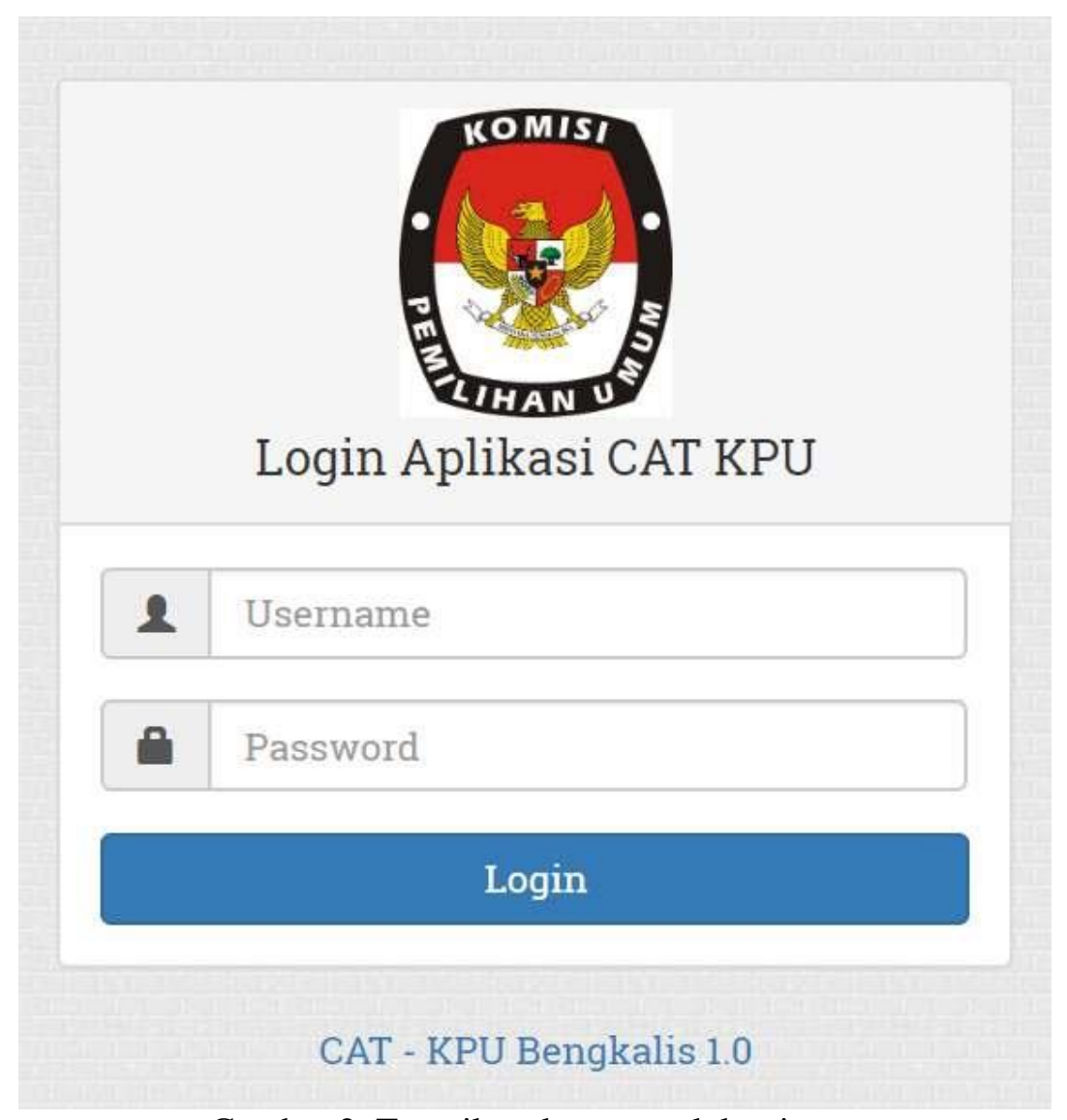

Gambar 2. Tampilan akses masuk ke sistem

Khusus untuk level 'Ketua Komisioner KPU' memiliki peran yang sangat penting dalam keamanan naskah soal. Password yang harus dimasukkan bagi level ini merupakan kombinasi dari semua komisioner. Hal ini untuk memastikan bahwa proses kunci soal, buka soal, distribusi soal, dan tarik soal bisa dilakukan setelah semua komisioner menginputkan karakter password masing-masing. Dengan kata lain, masing-masing komisioner memegang kunci untuk membuka gembok. Apabila ada 1 orang saja yang tidak hadir untuk membuka gembok maka gembok tidak akan terbuka.

- Layer II : Penguncian Soal

Soal yang sudah diinput oleh operator akan dikunci oleh komisioner KPU melalui level ketua kpu. Penguncian soal ini memastikan soal tidak bisa dilihat oleh semua level pengguna. Apabila terjadi kesalahan dalam penginputan soal, dibutuhkan ijin dari komisioner kpu dengan mengaktifkan fasilitas 'buka kunci soal'. 
- Layer III : Distribusi Soal

Soal bisa diakses oleh peserta salah satu syaratny adalah komisioner kpu mendistribusikan soal melalui fasilitas 'salurkan soal'. Pendistribusian soal bisa dilakukan apabila soal dalam keadaan terkunci. Hal ini untuk menjamin bahwa soal tidak bisa ada yang mengakses kecuali peserta.

- Layer IV : Penarikan Soal

Apabila semua sesi ujian telah selesai, untuk memastikan soal tidak beredar dilakukan proses penarikan soal melalui fasilitas 'tarik soal'.

- Layer V : Token

Setiap peserta harus memasukkan token untuk mengakses sesi ujian, yang disiapkan oleh system dan diberikan saat ujian akan berlangsung. Token memastikan bahwa peserta tidak dapat dibantu oleh pihak luar (joki) dalam menjawab soal nantinya.

- Layer VI : Waktu Akses Sesi

Waktu akses sesi adalah waktu yang disiapkan oleh Panitia melalui level 'operator' memberikan kesempatan akses untuk mengikuti Sesi Ujian. Peserta tidak dapat mengerjakan soal apabila waktu akses sesi belum berjalan

- Layer VII : Waktu Ujian

Waktu ujian adalah waktu yang disediakan untuk mengerjakan soal. Sistem akan melakukan countdown (hitung mundur) dan akan secara otomatis mengakhiri ujian apabila waktu telah selesai.

- Layer VIII : Pengacakan Soal

Sistem CAT menyiapkan fasilitas pengacakan soal (random) dari bank soal yang telah diinput sebelumnya. Hal ini untuk meminimalisir terjadinya kerjasama antar peserta (mencontek).

Fitur manajemen data operator mengizinkan seorang admin untuk bisa menambah akun yang bersangkutan agar dapat mengupload soal, mengadakan tes, serta melihat rekap data jawaban di sistem CAT. Selain menambahkan akun, admin bisa merubah/edit data akun operator, menghapus akun operator, mereset kata sandi akun operator dan menentukan sesi tes apa yang akan ditangani oleh operator. Untuk menggunakan fitur ini klik menu Data Operator seperti yang ada pada digambar dibawah ini maka akan muncul tampilan halaman manajemen data operator.

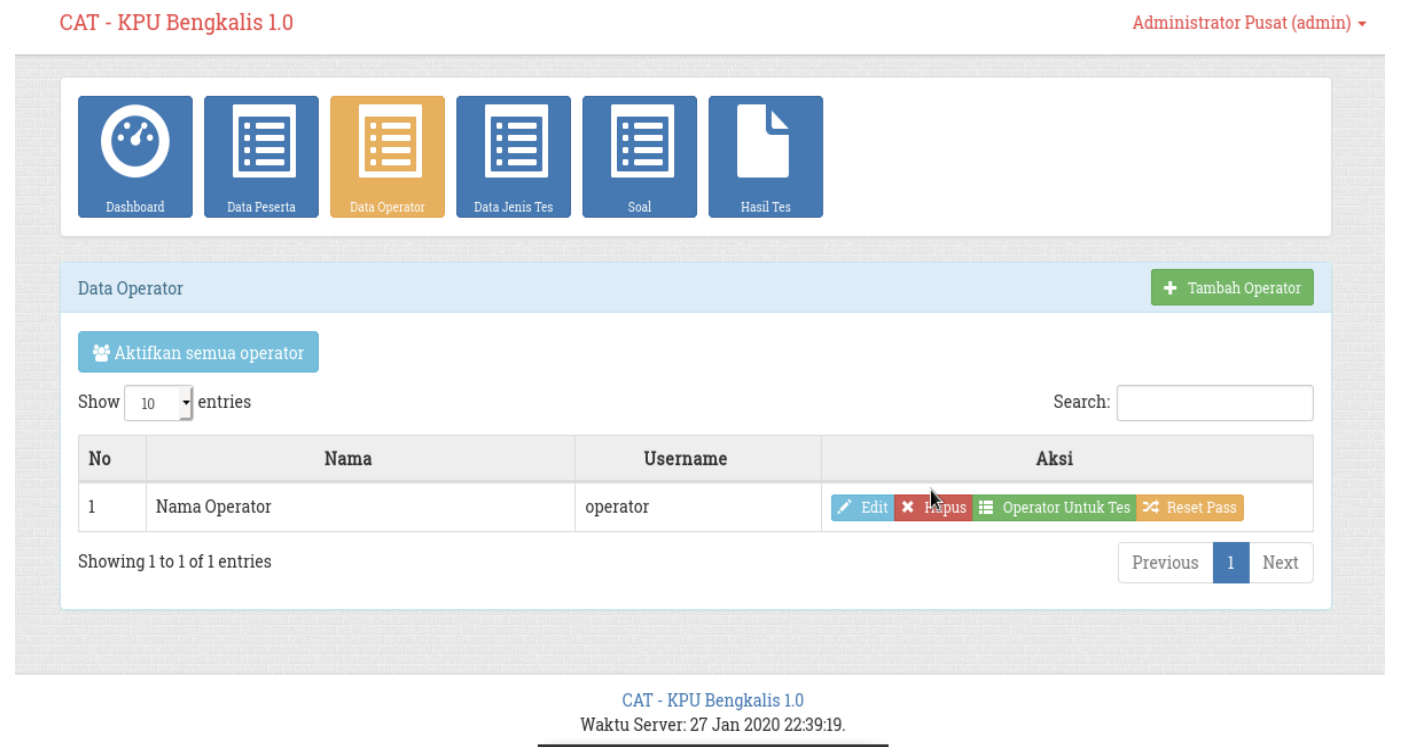

Gambar 3.Tampilan Keseluruhan Fitur Data Operator 
Tampilan berikut ini merupakan halaman dimana peserta akan mengerjakan soal ujian. Untuk menjawab soal, cukup dengan mengklik opsi jawaban. Jika ragu dengan jawaban anda, klik tombol ragu yang ada dibawah soal untuk menandai soal tersebut sebagai ragu. Tombol dibawah soal juga terdapat tombol navigasi berupa back untuk mundur ke soal sebelumnya, dan next untuk lanjut ke soal berikutnya. Jika berada di nomor soal terakhir akan muncul tombol selesai untuk menyelesaikan proses ujian.

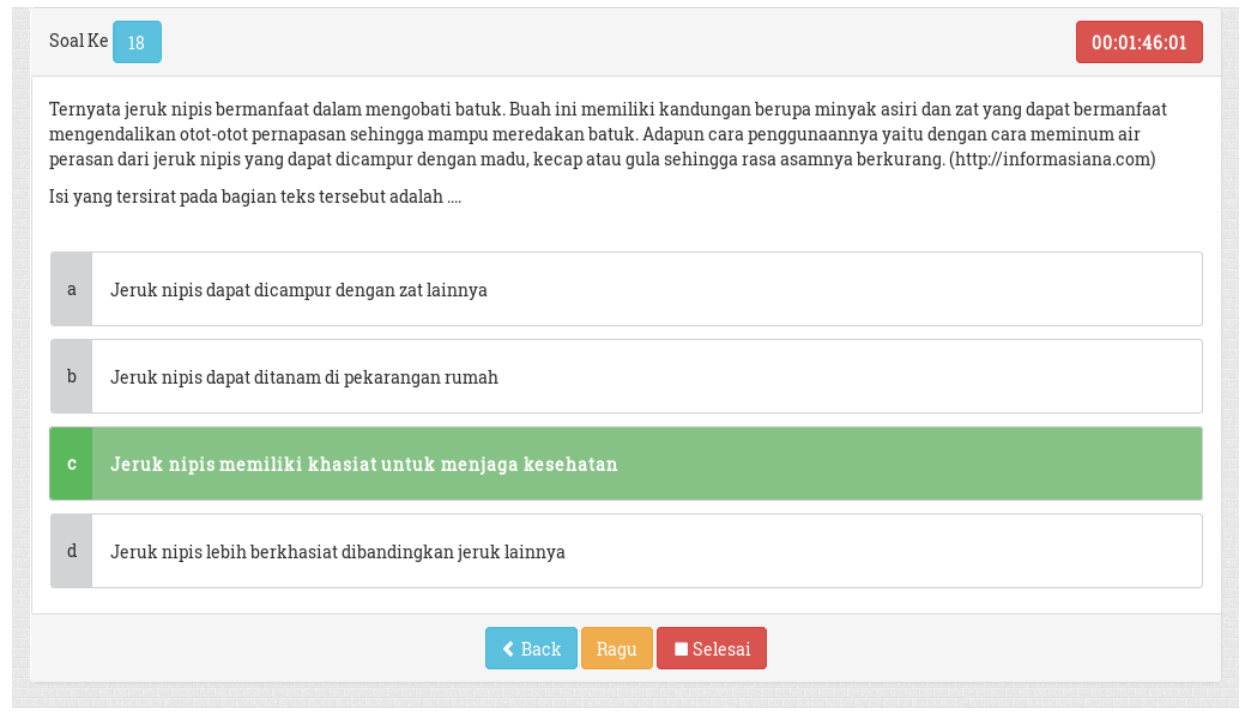

Gambar 4. Tampilan saat ujian

Anda juga bisa menyelesaikan ujian dengan tombol selesai ujian yang ada di pojok kanan atas.

\subsection{Secure Socket Layer}

Let's encrypt merupakan salah satu aplikasi Free Open Certificate Authority yang menyediakan fitur Sertifikat secure socket layer yang bisa digunakan secara gratis bagi khalayak ramai. Securesocket layer adalah suatu jalur terenkripsi yang berguna untuk mengamankan website dan web browser penggunanya. Pada url suatu website yang memiliki sertifikat SSL alamatnya akan berubah menjadi 'HTTPS' bukan 'HTTP'. Berbagai pihak hosting kini juga turut menyediakan fasilitas Secure socket layer secara gratis bagi pengguna. Berikut adalah cara melakukan installsai Securesocket layer

Adapun langkah- langkah cara install Let's Encrypt pada Cpanel yaitu sebagai berikut:

STEP 1: Masuk ke cpanel hosting

$$
\text { cPanel }
$$

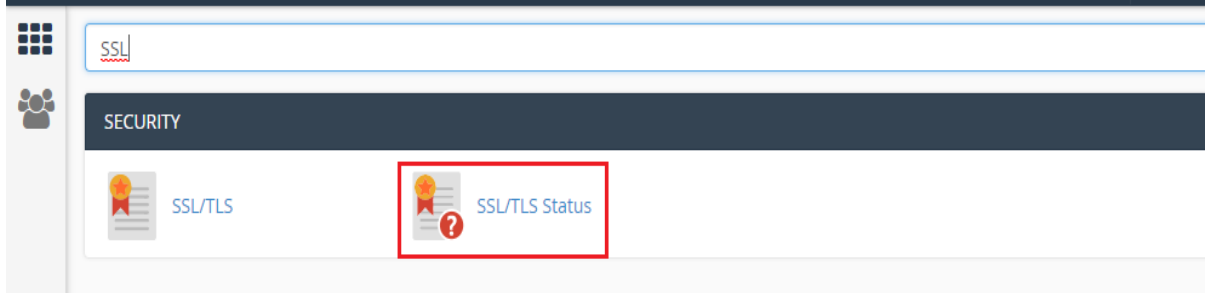

Gambar 5. Antarmuka Utama dari Cpanel

eISSN: 2477-3255, pISSN: 2086-4884 https://doi.org/10.31849/digitalzone.v11i1.3859 
STEP 2: Masuk ke menu SSL/TLS Status

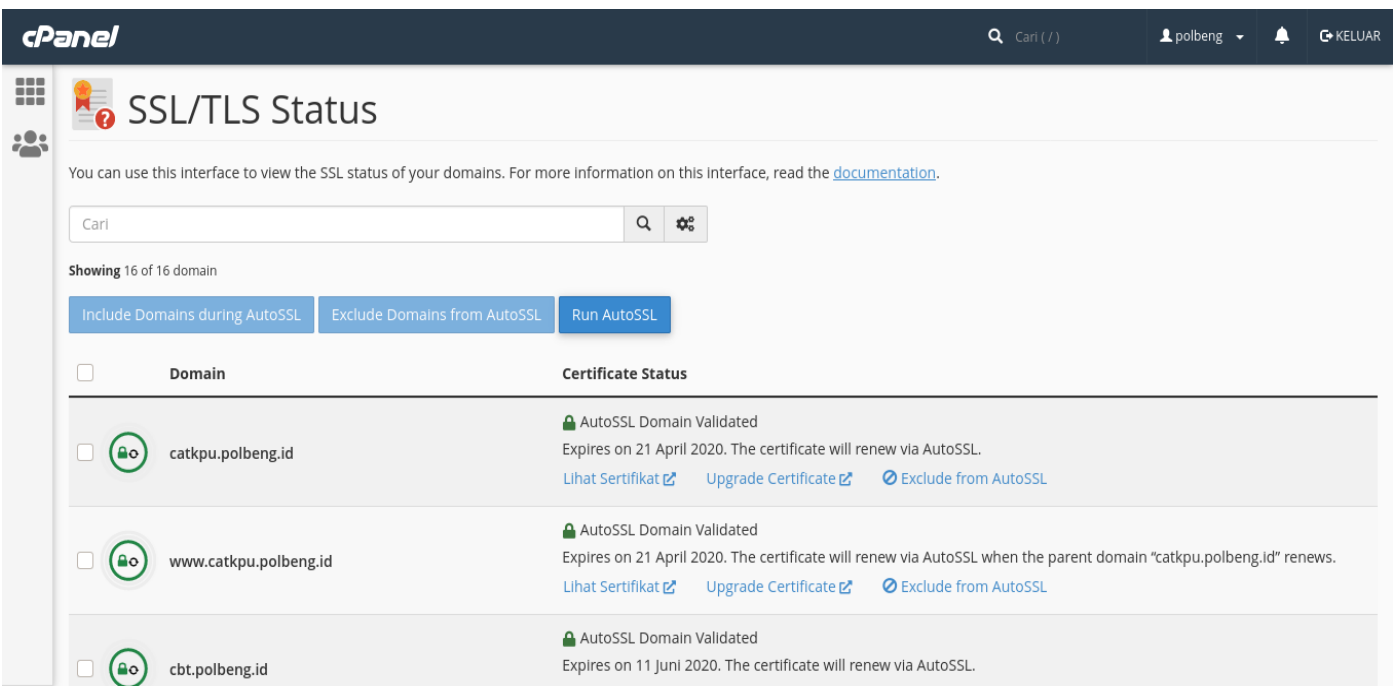

Gambar 6.Status dari SSL/TLS

Pada halaman ini akan muncul list domain-domain termasuk subdomain beserta status Aktivasi SSL didalamnya. Apabila statusnya merah berarti belum aktif dan apabila sudah berwarna hijau berarti sudah aktif.

STEP 3: Untuk mengaktifkan SSL yang masih merah silahkan centang di sebelah kiri domain atau subdomainnya

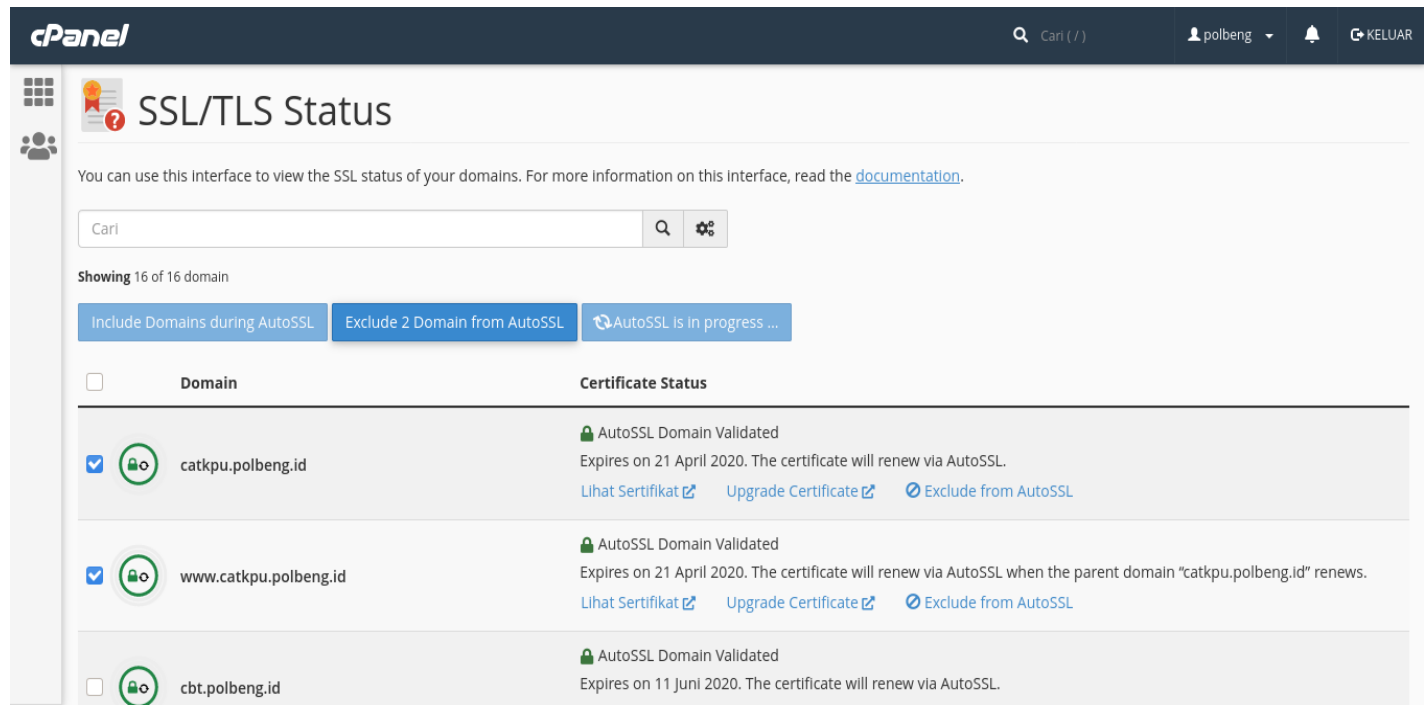

Gambar 7.Pemilihan SSL Status

STEP 5: Lalu klik Run Auto SSL, nantinya proses aktivasi SSL juga akan rampung pada proses ini. 


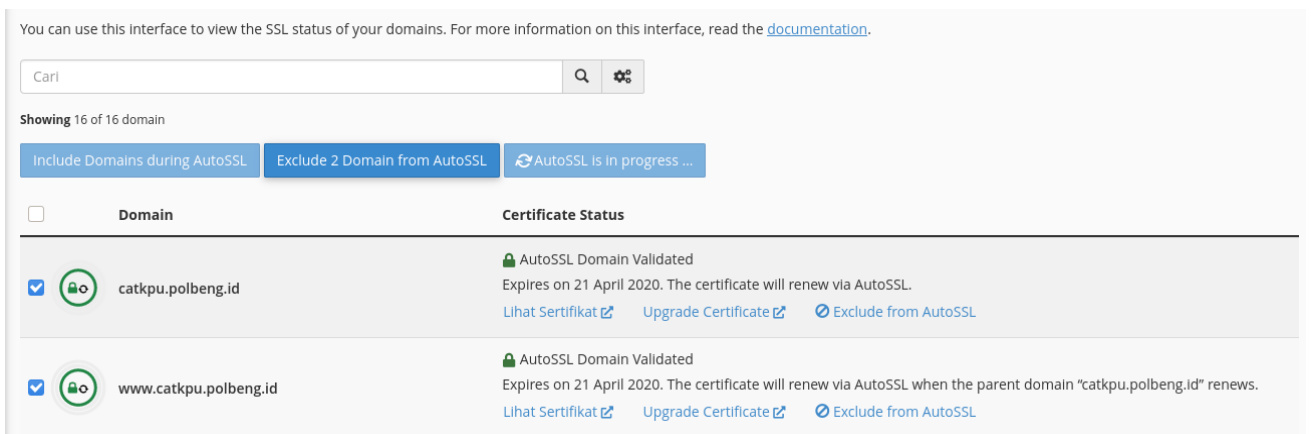

Gambar 8. Pemilihan Run AutoSSL

Penerapan SSL disini merupakan suatu penambahbaikan dari penelitian sebelumnya yang dilakukan oleh Khusnul Khatimah dengan judul "Pengembangan Prototipe Computer Assisted Test Menggunakan Arsitektur Model View Controller Pada Badan Kepegawaian Negara", Berikutnya penelitian oleh Utami Mizani Putri dan Sri Rahayu dengan judul "Aplikasi Computer Based Test Sebagai Alternatif Evaluasi Hasil Pembelajaran Siswa" menyebutkan Persentase kelayakan pengguna aplikasi yang dibuat berdasarkan faktor usability testing secara umum dapat disimpulkan bahwa sistem aplikasi ujian berbasis computer memiliki kualitas baik dan sangat layak untuk proses pengolahan data akademik siswa, Selanjutnya penelitian yang dilakukan oleh Ferry Putrawansyah degan judul "Aplikasi Computer Assisted Test Pada Penerimaan Mahasiswa Baru Sekolah Tinggi Teknologi Pagar Alam ketiga peneliatan diatas belum diterapkan teknik pengamanan system terhadap aplikasi CAT yang dibuat sehingga memungkinkan terjadinya perpindahan data yang tidak aman, Kehadiran adanya keamanan SSL di sebuah website ini sendiri dapat dikenali dengan mudah lewat adanya sebuah icon dengan bentuk kunci di kiri atas samping URL sebuah website dan awalan HTTPS, dan dalam penelitian ini SSL berhasil digunakan dengan baik

\subsection{Pengujian Aplikasi}

Pengujian sebuah aplikasi website dimaksudkan untuk tahu apakah aplikasi website tersebut dapat bekerja sesuai harapan pengguna meliputi test ketanggapan, kehandalan, stablititas dan skalabilitas. Pengujian pada umumnya dilakukan untuk mengevaluasi kinerja atau performa, melakukan perbandingan kinerja sistem untuk menentukan mana yang lebih baik dan menemukan sumber masalah yang terjadi. [10]

Pengujian pada aplikasi website yang nyata dapat merepresentasikan hasil yang lebih baik karena perangkat pengujian eksperimental tidak selalu dapat diterapkan pada studi kasus nyata. Sehingga, pengujian baik itu pengujian load-test, pengujian fault-test, maupun pengujian lainnya akan lebih berkontribusi bila dilakukan pada area web application yang riil. [11]

Pengujian dari aplikasi Web adalah salah satu tindakan penting yang diberikan guna penekanan khusus dalam jaminan kualitas. Ini adalah salah satu upaya dengan bertujuan untuk menemukan kesalahan dan kekurangan dalam perangkat lunak yang diuji, GtMetrix merupakan salah tool online yang bias digunakan untuk menganalisa performa dari sebuah website. GTMetrix dapat digunakan untuk menilai performa dari sebuah website berdasarkan sistem mereka dan sebagian berasal dari pustaka asli open source milik Google. System penilaian yang dilakukan oleh GTMetrix berdasarkan hasil ukur terhadap PageSpeed and YSlow dan memiliki 27 rekomendasi PageSpeed dan 18 rekomendasi YSlow. Dengan rentang score F (0-100\%) - A (0-100\%).

Ada banyak cara yang lain bisa dilakukan untuk melakukan optimasi sebuah website, agar load speed semakin kecil. Tentu saja dengan load speed website yang kecil, halaman website akan lebih cepat dibuka dan pengunjung website tidak merasa bosan untuk berlama-lama mengunjungi website nya. 


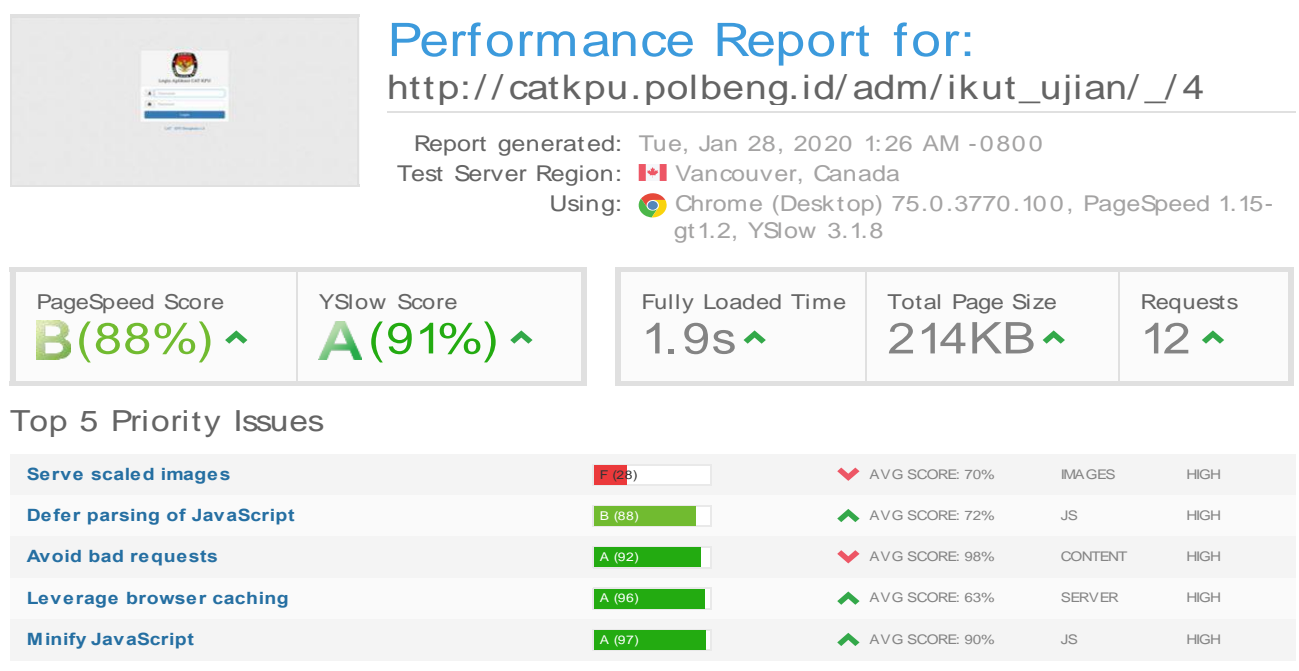

Gambar 9.Hasil Pengujian menggunakan. GTMetrix

Dari hasil pengujian menunujukan page speed yang di peroleh mencapai 88\% dan YSlow Score mencapai $91 \%$, artinya jika berdasarkan penilaian di GTMetrix berdasarkan PageSpeed and YSlow dan memiliki 27 rekomendasi PageSpeed dan 18 rekomendasi YSlow. Dengan score F $(0-100 \%)$ - A (0-100\%), maka performance dari aplikasi yang dibuat berada pada nilai Sangat Baik.

\section{Kesimpulan}

Alasan utama mengapa menggunakan sebuah website harus menggunakan sertivicate Secure socket layer adalah supaya dapat menjaga informasi sensitif selama dalam proses pengiriman di Internet dengan cara dienkripsi datanya, sehingga hanya penerima pesan yang menjadi tujuan pengiriman yang dapat memahami hasil dari enkripsi data tersebut. Hal ini sangat penting, karena data atau informasi yang kita kirimkan di Internet membutuhkan proses perjalanan dari komputer server ke komputer client. Ketika sertifikat Secure socket layer digunakan, informasi yang dikirimkan menjadi tidak dapat terbaca oleh siapapun kecuali computer yang memang dituju saat mengirim informasi atau data tersebut. Hal ini bertujuan untuk melindungi informasi atau data yang di kirimkan tersebut dari hackers dan pencuri data.

\section{Daftar Pustaka}

[1] A. Krispriana, N. Kumaladewi, and E. Rahajeng, "Sistem Informasi Computer Assisted Test (Cat) Kementerian Agama Republik Indonesia," Stud. Inform. J. Sist. Inf., vol. 9, no. 2, pp. 203-211, 2018, doi: 10.15408/sijsi.v9i2.7649.

[2] K. Khotimah, "Pengembangan Prototipe Computer Assisted Test (Cat) Menggunakan Arsitektur Model View Controller Pada Badan Kepegawaian Negara," J. Teknol., vol. 8, no. 2, p. 53, 2016, doi: 10.24853/jurtek.8.2.53-60.

[3] F. Putrawansyah and A. Arif, "Pengembangan Komputer Assisted Test (CAT) Pada Penerimaan Mahasiswa Baru Di Sekolah Tinggi Teknologi Pagaralam”, betrik, vol. 9, no. 01, pp. 34-45, Mar. 2018.

[4] U. Putri and S. Rahayu, "Aplikasi Computer Based Test (CBT) Sebagai Alternatif Evaluasi Hasil Pembelajaran Siswa”, JUSIFO, vol. 4, no. 2, pp. 153-164, Dec. 2018.

[5] C. Brubaker, S. Jana, B. Ray, S. Khurshid, and V. Shmatikov, "Using frankencerts for 
automated adversarial testing of certificate validation in SSL/TLS implementations," Proc. - IEEE Symp. Secur. Priv., pp. 114-129, 2014, doi: 10.1109/SP.2014.15.

[6] L. B. De Guzman, A. M. Sison, and R. P. Medina, "Implementation of enhanced MD5 algorithm using SSL to ensure data integrity," ACM Int. Conf. Proceeding Ser., pp. 7175, 2019, doi: 10.1145/3310986.3311027.

[97] D. Hari, P. Dewa, E. S. Pramukantoro, and D. P. Kartikasari, "Analisis Mekanisme Keamanan Antara TLS / SSL Dan Crypto Pada Komunikasi IoT Middleware Dengan Subscriber Berbasis Protokol HTTP,” vol. 2, no. 10, pp. 4027-4033, 2018.

[8] H. Pranata, L. A. Abdillah, and U. Ependi, "Analisis Keamanan Protokol Secure Socket Layer (SSL) Terhadap Proses Sniffing di Jaringan," pp. 21-22, 2015, [Online]. Available: http://arxiv.org/abs/1508.05457.

[9] Hutrianto and F. Syakti, "Sistem Informasi Geografis Penderita Malaria pada Kelurahan Cereme Taba Kota Lubuklinggau," Digit. Zo. J. Teknol. Inf. dan Komun., vol. 10, no. 2, pp. 178-188, 2019, doi: 10.31849/digitalzone.v10i2.3134.

[10] D. Gea, "Pengujian Kualitas Website Ditinjau dari Perspektif Accessibility, Experience, Marketing dan Technology," ComTech Comput. Math. Eng. Appl., vol. 5, no. 1, p. 35, 2014, doi: 10.21512/comtech.v5i1.2578.

[11] S. R. Dimas Widya Liestio Pamungkas, "Pengujian Aplikasi Web - Tinjauan Pustaka Sistematis," J. IPTEK Pangan, vol. 23, no. 1, pp. 17-24, 20190.31284/j.iptek.2019.v23i1. 